\title{
Regulation of Murine Myometrial Contraction by Ginger Extract Via Activation of Voltage Dependent $\mathrm{Ca}^{2+}$ Channels
}

\author{
Seung Hwa Hong ${ }^{1}$, Kyu-Sang Kyeong ${ }^{2}$, Il Woon $\mathrm{Ji}^{1}$, Eun-Hwan Jeong ${ }^{1}$, Hak Soon Kim ${ }^{1}$, Bang Yeon \\ Hwang $^{3}$, Chul Lee ${ }^{3}$, Seung Myeung Son ${ }^{4}$, Young Chul Kim ${ }^{5 *}$, Ra Young You ${ }^{5}$, Sang Jin Lee ${ }^{5}$, Kyuen Na ${ }^{6}$, \\ Soyoung Ahn ${ }^{6}$, Ji Young Park ${ }^{7}$, Chan Hyung Kim ${ }^{8}$, Hun Sik Kim ${ }^{8}$, Woong Choi ${ }^{8}$, Yeon Jin Park ${ }^{9}$ and
} Wen-Xie Xu${ }^{10}$

${ }^{1}$ Department of Obstetrics and Gynecology, College of Medicine, Chungbuk National University(CBNU), Chungdae-ro 1, Seowon-gu, Cheongju, Chungbuk, 28644, Korea

${ }^{2}$ Department of Obstetrics and Gynecology, Hallym Univ, Dongtam, Sared Heart Hospital, Heaseong, Korea

${ }^{3}$ Department of Pharmacy, CBNU, Cheongju, Chungbuk, 28644, Korea

${ }^{4}$ Department of Pathology, CBNU, Cheongju, Chungbuk, 28644, Korea

${ }^{5}$ Department. of Physiology, College of Medicine, CBNU, Cheongju, Chungbuk, 28644, Korea

${ }^{6}$ A Medical student, College of Medicine, CBNU, Cheongju, Chungbuk, 28644, Korea

${ }^{7}$ Deptartment of Psychiatry, CBNU, Cheongju, Chungbuk, 28644, Korea

${ }^{8}$ Dept. of Pharmacology, College of Medicine, CBNU, Cheongju, Chungbuk, 28644, Korea

${ }^{9}$ Department of Obstetrics and Gynecology, Chengju ST. Mari's Hospital, Cheonwon-Gu, Jusung-Ro, Cheongju, Chungbuk, 173-19, Korea

${ }^{10}$ Department of Physiology, College of Medcine, Shanghai Jiaotong University, 800 Dongchun Rd. Shanghai, 200240, P.R. China

*Corresponding author: Young Chul Kim, Department of Physiology, Chungbuk National University, College of Medicine, Chungdae-ro 1, Seowon-Gu, Cheongju 28644, Korea

Co-Corresponding author: Woong Choi, Department of Pharmacology, Chungbuk National University, College of Medicine, Chungdae-ro 1, Seowon-Gu, Cheongju 28644, Korea

\section{ARTICLE INFO}

Received: 幽 August 09, 2019

Published: 幽 August 21, 2019

Citation: SH Hong, KS Kyeong, IW Ji, EH Jeong, YC Kim, et al., Regulation of Murine Myometrial Contraction by Ginger Extract Via Activation of Voltage Dependent $\mathrm{Ca}^{2+}$ Channels. Biomed J Sci \& Tech Res 20(4)-2019. BJSTR. MS.ID.003499

Keywords: Myometrium; $\mathrm{VDCC}_{\mathrm{L}}$; $\mathrm{VDCC}_{\mathrm{T}}$; Oxytocin; Ginger

\section{ABSTRACT}

Voltage-dependent L-type $\mathrm{Ca}^{2+}$ channel $\left(\mathrm{VDCC}_{\mathrm{L}}\right)$ and T-type $\mathrm{Ca}^{2+}$ channel $\left(\mathrm{VDCC}_{\mathrm{T}}\right)$ in murine myometrium was identified in murine myometrium. Its regulatory functions were characterized by using extracts of ginger. Methanol extract of ginger was used to obtain dichloromethane fraction (Gin C). Spontaneous uterine contractions were enhanced by BayK 8644, a VDCC ${ }_{\mathrm{L}}$ activator. However, such effects were inhibited by nifedipine (a VDCC $C_{\mathrm{L}}$ blocker) and mibefradil (a VDCC $\mathrm{T}_{\mathrm{T}}$ blocker). Mibefradil also inhibited oxytocin (OXT), prostaglandins $\mathrm{F}_{2 \alpha}\left(\mathrm{PGF}_{2 \alpha}\right)$, and prostaglandins $\mathrm{E}_{2}\left(\mathrm{PGE}_{2}\right)$-induced contractions. However, application of BayK 8644 in the presence of mibefradil recovered those contractions in a nifedipine-sensitive manner. These results suggest that both $\mathrm{VDCC}_{\mathrm{L}}$ and $\mathrm{VDCC}_{\mathrm{T}}$ are important in the regulation of murine myometrial contractions. Gin C $(200 \mathrm{mg} / \mathrm{mL})$ completely inhibited spontaneous contractions of murine uterus reversibly. The inhibition by Gin C on spontaneous contractions independent of L-NAME, $\mathrm{K}^{+}$channel blockers, and nerve blockers. High $\mathrm{K}^{+}(50 \mathrm{mM})$-induced contraction in the presence and absence of cyclopizonic acid (CPA) was also completely inhibited by Gin $\mathrm{C}$, respectively. In addition, Gin C inhibited oxytocin (OXT; $10 \mathrm{nM}$ )-induced contraction independent of L-NAME and blockers of protein kinases. Prostaglandin $\mathrm{F}_{2 \mathrm{a}}\left(\mathrm{PGF}_{2 \mathrm{a}}\right)$ - and acetylcholine (ACh) produced contractions were also inhibited by Gin C. These results raise the possibility that Ginger extracts $\mathrm{C}$ inhibits spontaneous, high $\mathrm{K}^{+}-$, OXT-, $\mathrm{PGF}_{2 \mathrm{a}}$ and ACh-induced contractions by inhibition of $\mathrm{VDCC}_{\mathrm{L}}$ in mouse uterine longitudinal smooth muscle. 


\section{Introduction}

Ginger (Zingiber officinae Roscoe) is a flowering plant in family Zingiberaceae whose roots is widely used as an ingredient in both cooking and East Asian traditional medicine. Ginger is traditionally used to treat fever, nausea, vomiting, and uterine disorders. Ginger has also been used to treat paralytic ileus in Japan [1-4]. It has

been reported that ginger can regulate contractility of uterine, gastrointestinal (GI) tract, and airway smooth muscle. Rat uterine muscle tone and spontaneous contractions can also be enhanced by ginger extract [5]. Such enhancing effect on the contraction is produced by activation of voltage-dependent L-type $\mathrm{Ca}^{2+}$ channels $\left(\right.$ VDCC $_{\mathrm{L}}$ ) and release of $\mathrm{Ca}^{2+}$ from sarcoplasmic reticulum [5]. Other reports have suggested similar enhancing effects of ginger extract on rabbit uterine smooth muscle tone and its spontaneous contractions [6]. In general, $\mathrm{VDCC}_{\mathrm{L}}$ is essential for the regulation of smooth muscle contractility in many species [7-10]. Nifedipine,

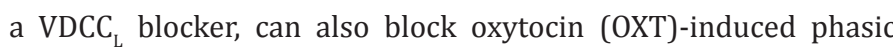
contraction in murine myometrium (unpublished data). Regulatory effects of ginger on contractility of uterine, gastrointestinal (GI) tract, and airway smooth muscle have been reported $[5-6,11]$.

Ginger also can improve gastric emptying and motility, intestinal contractility, and irritable bowel syndrome (IBS) in the GI tract [12-13]. In addition, ginger extract and its components can also inhibit motility of GI including the lower esophageal sphincter (LES) [14-15]. Other studies have suggested that ginger extract has regulatory effects on airway and vascular smooth muscle [16-17]. However, the mechanism of action involved in the effect of ginger extract on these organs remains unclear. In this study, we found that ginger extract could inhibit uterine smooth muscle contractility by blocking VDCCs. Since ginger is safe for humans, ginger might have potential to be developed as a tocolytic agent to relieve excessive uterine contractions.

\section{Materials and Methods}

\section{Tissue Preparation for Isometric Contraction}

All experiments were performed in accordance with the guidelines for animal care and use provided by Chungbuk National University (CBNUA-383-11-01; CBNUA-597-13-02; CBNUA-719-14-01; CBNUA-863-15-01; CBNUA-988-16-01; CBNUA-1125-17-02; CBNUA-1162-18-02). All animal experiments were conducted in accordance with the National Institutes of Health (USA) Guidelines for the Care and Use of Laboratory Animals (the Guide for the Care and Use of Laboratory Animals (8th edition, National Academies Press)) and were approved by the Chungbuk National University Medical School Research Institutional Animal Care and Use Committee (Korea). Female non-pregnant mouse was used in this whole study. Institute of Cancer Research (ICR) mice (age, 10-12 weeks) were anaesthetized with fluoromethyl 2,2,2-trifluoro-1(trifluoromethyl) ethyl ether (Sevoflurane; Maruishi Pharma., Osaka, Japan) and/or chloroform and killed by cervical dislocation. Their uteri were cut open from the neck to the end of uterine horns, rinsed in Krebs-Ringer bicarbonate (KRB) solution, and pinned on a Sylgard plate to maintain their original shape. Connective tissues were removed, and these uteri were cut.

The endometrium was separated from other muscle layers in KRB solution. Longitudinal muscle strips $(1 \times 5 \mathrm{~mm})$ were mounted onto vertical chambers ( 25 and $75 \mathrm{~mL}$ ) in an isometric contractile measurement system with one end of the tissue tied tightly to a fixed holder while the other end of the tissue was linked to a force transducer (Harvard Instruments, Holliston, MA, USA) by a hook. The force transducer was connected to a Power Lab-Data Acquisition System and a personal computer running Charter v5.5 software (ADinstruments, Boulder, CO, USA) to measure isometric contractions. Each strip was stretched passively to resting tension for 1-2 hours after equilibration for 1.5 hours. Contractile responses of the strip to high $\mathrm{K}^{+}(50 \mathrm{mM})$ were repeated twice.

\section{Ginger Extraction}

Dried ginger powder was purchased from a local company and $300 \mathrm{~g}$ was extracted twice with methanol for $2 \mathrm{~L} 24$ hours at room temperature. Four liters of this methanol extract was dried in a rotary evaporator to yield $21 \mathrm{~g}$ of precipitate. The precipitate was resuspended in $500 \mathrm{ml}$ of water and mixed with $500 \mathrm{ml}$ of dichloromethane. The mixture was set at room temperature until water and dichloromethane phases separated clearly. Water and dichloromethane fractions were then collected and freeze-dried. Yields of water and dichlromethane fractions were $9.4 \mathrm{~g}$ and $11.4 \mathrm{~g}$, respectively. We already got patent in Korea (Patent No: 1018089440000; Title: Composition for preventing and treating dysmenorrhea and premature labor comprising non-polar solvent subfraction from Zingiber officinale extract; Web site: http:// engportal.kipris.or.kr/engportal/search/total_search.do)

\section{Solution and Drugs}

KRB solution ( $\mathrm{CO}_{2} /$ bicarbonate-buffered Tyrode) contained (in $\mathrm{mM}$ ) the following: $122 \mathrm{mM} \mathrm{NaCl}, 4.7 \mathrm{mM} \mathrm{KCl}, 1 \mathrm{mM} \mathrm{MgCl}, 2 \mathrm{mM}$ $\mathrm{CaCl}_{2}, 15 \mathrm{mM} \mathrm{NaHCO}_{3}, 0.93 \mathrm{mM} \mathrm{KH}_{2} \mathrm{PO}_{4}$, and $11 \mathrm{mM}$ glucose $(\mathrm{pH}$ 7.3-7.4, bubbled with $5 \% \mathrm{CO}_{2} / 95 \% \mathrm{O}_{2}$ ). Equimolar concentration of $\mathrm{Na}^{+}$was replaced with $\mathrm{K}^{+}$to make high $\mathrm{K}^{+}(50 \mathrm{mM})$ solution. The external solution was changed with solution that had been bubbled with $5 \% \mathrm{CO}_{2} / 95 \% 02,36{ }^{\circ} \mathrm{C}$ ) in a water bath before application. Various blockers were applied for 12-15 minutes before application of Gin C. Then a $\mathrm{K}^{+}$channel blocker cocktail (KBC) was applied before application of stimulators to block each $\mathrm{K}^{+}$ channel's responses. KBC contained 4-aminopyridine (4-AP, $2 \mathrm{mM}$ ), tetraethylammonium (TEA, $5 \mathrm{mM}$ ), apamin (APA, $300 \mathrm{nM}$ ), and glibenclamide (Glib, $20 \mu \mathrm{M}$ ). To rule out nerve mediated response, a nerve blocker cocktail (NBC) was used. NBC contained tetrodotoxin (TTX, $0.4 \mu \mathrm{M}$ ), guanethidine (1 $\mu \mathrm{M})$, and atropine (ATR, $1 \mu \mathrm{M})$ [7-9]. All drugs used in this study were purchased from Sigma-Aldrich (St. Louis, MO, USA). 


\section{Statistics}

Data are expressed as means \pm standard errors of the mean (SEM). Statistical significance was measured using analysis of variance (ANOVA) and student's t-test. Any p-value less than 0.05 was regarded as statistically significant.

\section{Results}

\section{Isometric Contraction of Mouse Uterine Longitudinal Smooth Muscle}

Oxytocin (OXT, $10 \mathrm{nM}$ ) produced tri-phasic contractions, showing an initial contraction followed by a tonic contraction overlapped with a phasic contraction (Figure 1). Uterine smooth muscle produced spontaneous contractions of $1.4 \pm 0.25 \mathrm{~g}$ with a frequency of $0.5 \pm 0.05$ cycles/min (Figure $1 \mathrm{~B} ; \mathrm{n}=43$ ). $\mathrm{VDCC}_{\mathrm{L}}$ activator BayK 8644 enhanced the strength and the frequency of uterine spontaneous contractions to $215 \pm 49.0 \%$ and 228 $\pm 29.0 \%$ of the control [ $n=4$ each, $p<0.05$, (Figure 1B)]. These enhanced contractions caused by BayK 8644 were completely inhibited by nifedipine ( $2 \mu \mathrm{M}, \mathrm{n}=3, \mathrm{p}<0.05)$. Phasic OXT-induced contractions were completely blocked by $2 \mu \mathrm{M}$ nifedipine [(Figure 1C), $\mathrm{n}=4, \mathrm{p}<0.05]$. The strength and frequency of OXT-induced phasic contractions were also enhanced significantly by BayK 8644 compared to those of the control $(n=6$, respectively, $\mathrm{p}<0.05$; data not shown). These enhanced OXT-induced phasic contractions were completely inhibited by nifedipine $(2 \mu \mathrm{M}, \mathrm{n}=6, \mathrm{p}<0.05$, data not shown).

A

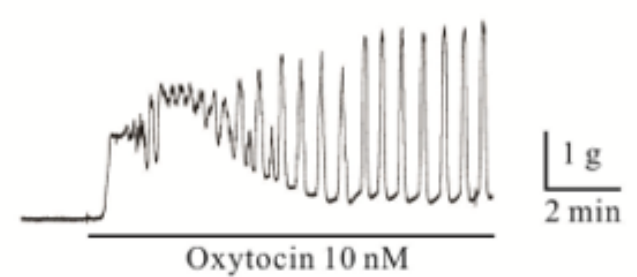

B

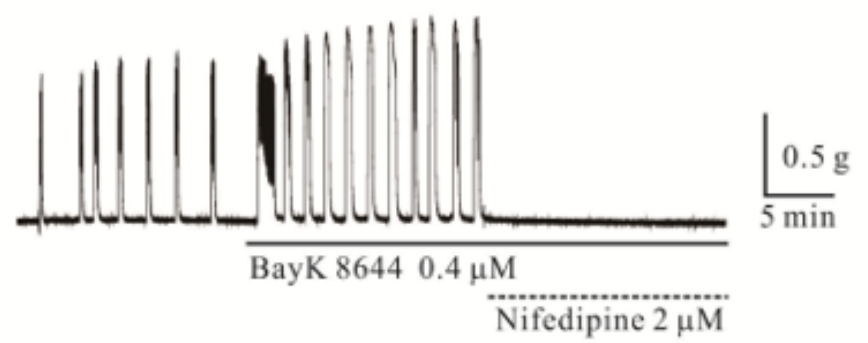

C
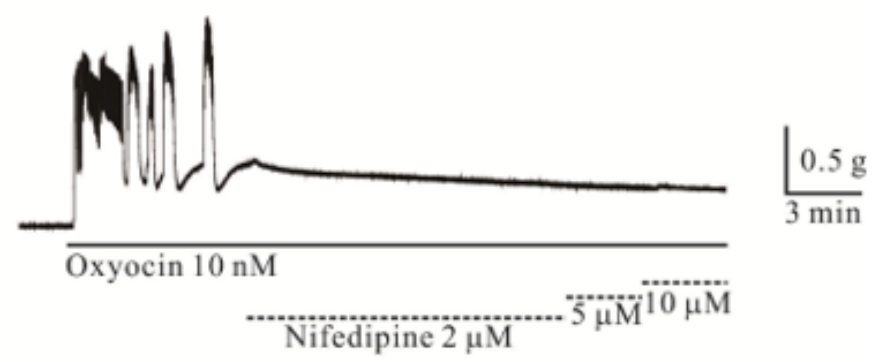

(A) Oxytocin (OXT, $10 \mathrm{nM}$ ) produced tri-phasic contractions, such as initial contraction, followed by tonic contraction overlapped with phasic contraction. (B) Uterine smooth muscle produced spontaneous contractions of $1.4 \mathrm{~g}$ with a frequency of 0.5 cycles/min. BayK 8644 (voltage-dependent L-type $\mathrm{Ca}^{2+}$ channel [VDCC ${ }_{\mathrm{L}}$ ] activator) enhanced uterine spontaneous contraction and frequency to $215 \%$ and $228 \%$ of the control. The spontaneous and enhanced contractions by BayK 8644 were completely inhibited by nifedipine $(2 \mu \mathrm{M})$. (C) OXT-induced phasic contractions was blocked by $2 \mu \mathrm{M}$ nifedipine.

Figure 1: Isometric contractions of mouse uterine longitudinal smooth muscle.

\section{Inhibitory Effect of Ginger Extract (Gin C) on High $\mathrm{K}^{+}$} Induced Contraction

As shown in Figure 2, high $\mathrm{K}^{+}(50 \mathrm{mM})$ produced tonic contraction in uterine smooth muscle $(1.8 \pm 0.43 \mathrm{~g}, \mathrm{n}=20)$. In the presence of cyclopiazonic acid (CPA), high $\mathrm{K}^{+}(50 \mathrm{mM})$-induced contraction of $1.4 \pm 0.75 \mathrm{~g}(\mathrm{n}=7)$ and was completely blocked by application of nifedipine [2-5 $\mu \mathrm{M}, \mathrm{n}=7$; (Figure 2B)]. Gin C at 40-400 $\mathrm{mg} / \mathrm{mL}$ inhibited high $\mathrm{K}^{+}$-induced contractions (Figure $2 \mathrm{C}$ ). Gin $\mathrm{C}$ at 100,200 , and $400 \mathrm{mg} / \mathrm{mL}$ inhibited high $\mathrm{K}+$-induced contractions to $46 \pm 10.2 \%, 15 \pm 4.9 \%$, and $3.4 \pm 1.4 \%$, respectively, of the control $\left(\mathrm{p}<0.05 ; \mathrm{n}=5\right.$, data not shown). Gin $\mathrm{C}$ also inhibited high $\mathrm{K}^{+}(50$ $\mathrm{mM}$ )-induced contraction in the presence of CPA completely (400 $\mathrm{mg} / \mathrm{mL}, \mathrm{n}=5$; data not shown). 
A

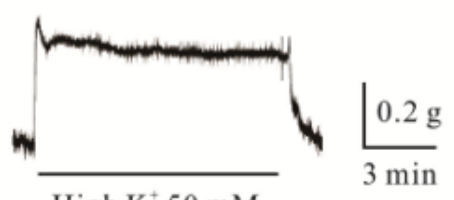

High $\mathrm{K}^{+} 50 \mathrm{mM}$
B

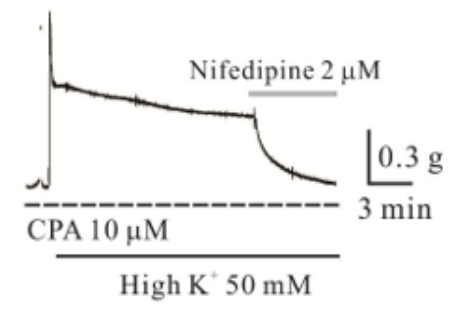

$\mathrm{C}$

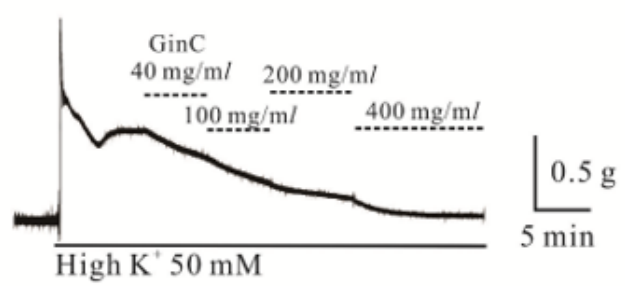

High $\mathrm{K}^{+}(50 \mathrm{mM})$ produced tonic contraction of longitudinal smooth muscle in the absence $(\mathrm{A})$ and presence (B) of cyclopiazonic acid (CPA). C: Gin C (40-400 mg/mL) inhibited high $\mathrm{K}^{+}(50 \mathrm{mM})$-induced contractions of mouse uterine longitudinal smooth muscle.

Figure 2: Inhibitory effect of ginger extract (Gin C) on high $\mathrm{K}^{+}(50 \mathrm{mM})$-induced contractions of mouse uterine longitudinal smooth muscle

\section{Inhibitory Effect of Ginger Extract (Gin C) on Spontaneous Contraction of Mouse Uterine Longitudinal Smooth Muscle}

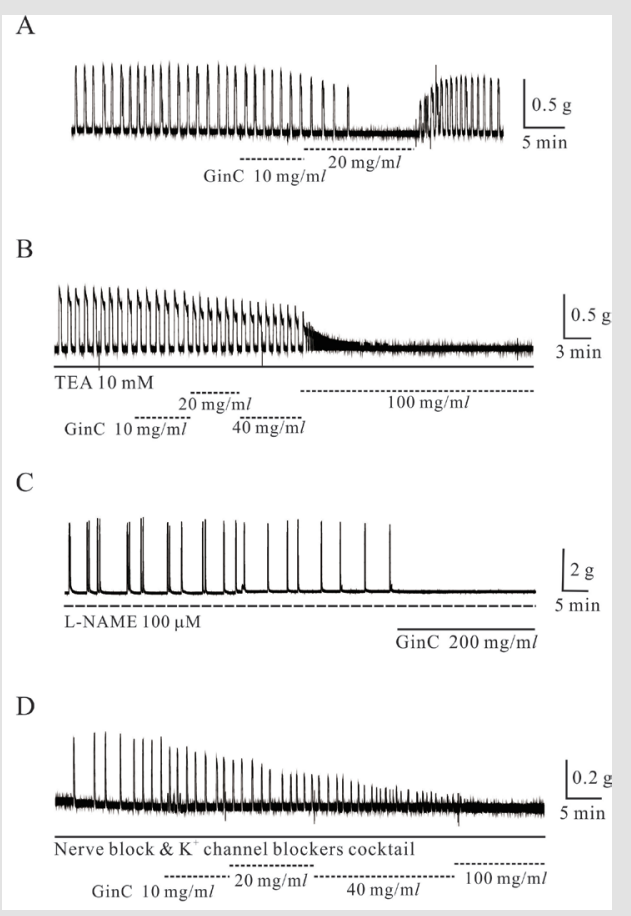

A: Spontaneous contractions of longitudinal smooth muscle were reversibly inhibited by Gin C (10 and $20 \mathrm{mg} / \mathrm{mL})$.

B: Gin C produced relaxation in the presence of tetraethylammonium (TEA, $10 \mathrm{mM})$, which block $\mathrm{Ca}^{2+}$-activated $\mathrm{K}^{+}\left(\mathrm{K}^{\mathrm{ca}}\right)$ channels.

C: The inhibitory effect of Gin C on spontaneous contractions was not mediated by nitric oxide (NO). Gin C (200 mg/mL) inhibited spontaneous contractions in the presence of NG-nitro-L-arginine methyl ester (L-NAME; $100 \mu \mathrm{M}$, an NO synthesis inhibitor).

D: The effect of Gin C on the uterine smooth muscle contractions in the presence of the $\mathrm{K}^{+}$channel blocker cocktail (KBC) and nerve blockers was also observed.

Figure 3: Inhibitory effect of ginger extract (Gin C) on spontaneous contractions of mouse uterine longitudinal smooth muscle. 
Spontaneous contractions of longitudinal smooth muscle were inhibited by Gin C (10-200 mg/mL) in a reversible manner (Figure 3). Gin $\mathrm{C}$ at $10,20,100$, and $200 \mathrm{mg} / \mathrm{mL}$ inhibited spontaneous contractions to $46 \pm 14.7 \%, 40 \pm 15.5 \%, 26 \pm 19.3 \%$, and $0 \%$, of the control, respectively ( $\mathrm{p}<0.05 ; \mathrm{n}=5,7,5$, and 3 , respectively). Gin $\mathrm{C}$ at 100 and $200 \mathrm{mg} / \mathrm{mL}$ also inhibited basal tone slightly to $-0.03 \pm$ $0.01 \mathrm{~g}$ and $-0.05 \pm 0.01 \mathrm{~g}$, respectively ( $\mathrm{n}=5$ and $\mathrm{n}=3$, respectively). However, the inhibitory effect of Gin $\mathrm{C}$ on spontaneous contractions was not mediated by nitric oxide (NO): Gin C at $100 \mathrm{mg} / \mathrm{mL}$ inhibited spontaneous contractions completely in the presence of NO synthesis inhibitor NG-nitro-L-arginine methyl ester (L-NAME, $100 \mu \mathrm{M} ; \mathrm{n}=9$; Figure 3C).

\section{Effects Of $\mathrm{K}^{+}$Channel and Nerve Blockers on Gin C-Induced Relaxation in Mouse Uterine Smooth Muscle}

We studied the effect of Gin C on uterine smooth muscle contractions in the presence of KBC and NBC to investigate whether $\mathrm{K}^{+}$channels and nerves were activated during Gin C-induced relaxation. Gin $C$ produced relaxation $(n=2)$ in the presence of tetraethylammonium (TEA, $10 \mathrm{mM}$ ) which blocked $\mathrm{Ca}^{2+}$-activated $\mathrm{K}^{+}\left(\mathrm{K}^{\mathrm{ca}}\right)$ channels (Figure $\left.3 \mathrm{~B}\right)$. Gin C-induced relaxation was also observed in the presence of KBC and NBC (Figure 3D). Gin C at 100 and $200 \mathrm{mg} / \mathrm{l}$ produced relaxation up to $14 \pm 7.3 \%$ and $0 \pm 0 \%$, respectively, of the control ( $n=3$ and $n=2$, respectively).

\section{Inhibitory Effects of Gin C on Oxt- And High $\mathrm{K}^{+}$-Induced Mouse Uterine Longitudinal Smooth Muscle Contractions}

Gin C inhibited OXT-induced uterine smooth muscle contractions. Gin C at 40, 100, 200, and $400 \mathrm{mg} / \mathrm{mL}$ inhibited OXTinduced phasic contractions to $56 \pm 12.2 \%, 54 \pm 11.6 \%, 2 \pm 2 \%$, and $0 \%$ of the control, respectively (Figure $4 \mathrm{~A}),(\mathrm{p}<0.05 ; \mathrm{n}=16,14,12$, and 2 , respectively). In the presence of L-NAME, Gin $\mathrm{C}$ at 100 and $200 \mathrm{mg} / \mathrm{mL}$ also inhibited OXT-induced phasic contractions to $20 \pm$ $7.0 \%$ and $0 \%$, respectively, of the control $(\mathrm{p}<0.05 ; \mathrm{n}=10$ and $\mathrm{n}=$ 6 , respectively; data not shown). In addition, Gin C at 100, 200, and $400 \mathrm{mg} / \mathrm{mL}$ inhibited high $\mathrm{K}^{+}$-induced contractions to $46 \pm 10.2 \%$, $15 \pm 4.9 \%$, and $3.4 \pm 1.4 \%$, respectively, of the control $(\mathrm{p}<0.05 ; \mathrm{n}=$ 5 , data not shown; Figure 4).

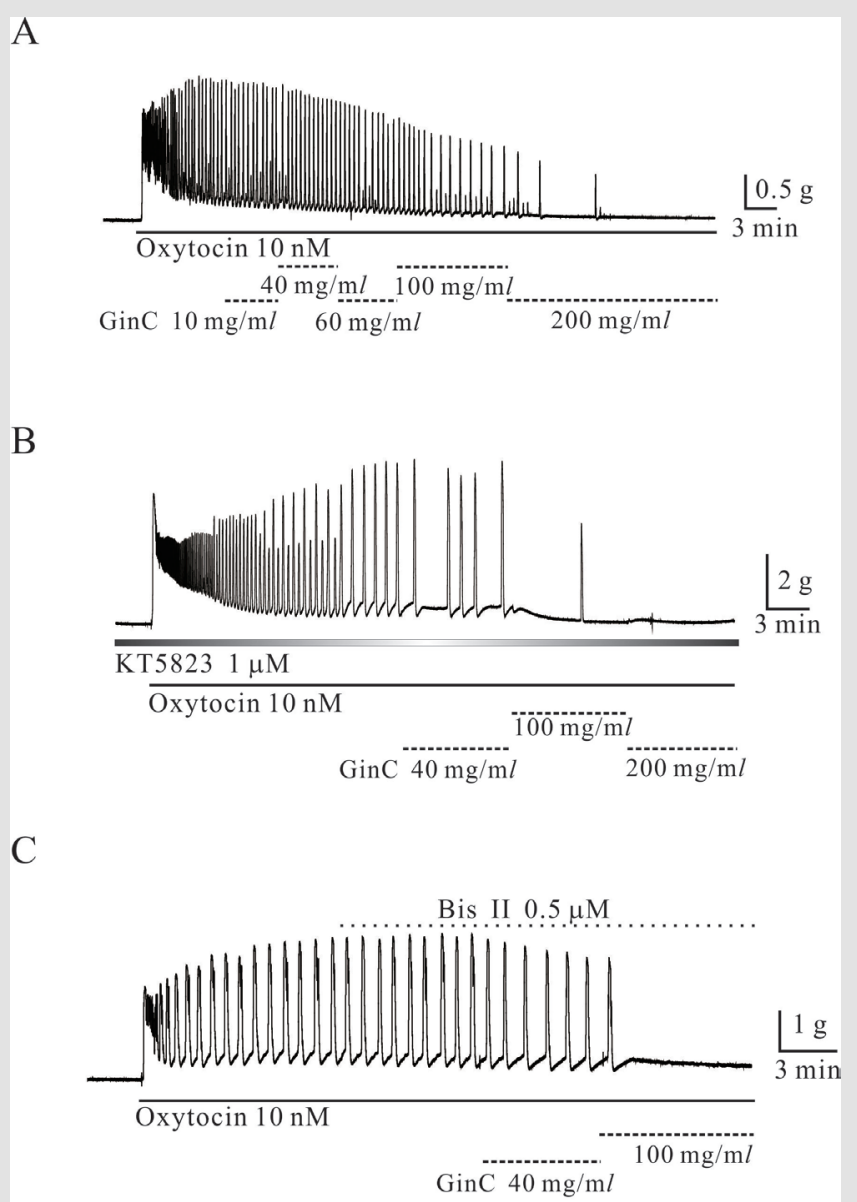

Gin C inhibited OXT-induced uterine smooth muscle contractions. A: OXT-induced contractions of uterine smooth muscle were also inhibited by Gin C. Gin C $(10-200 \mathrm{mg} / \mathrm{mL})$ inhibited OXT-induced phasic contractions to $56 \%, 54 \%, 2 \%$, and 0 $\%$ of the control. B: Inhibitory effects of Gin C on OXT-induced contractions were studied in the presence of KT 5823, which inhibit PKG. OXT-induced contractions was inhibited by Gin C in the presence of KT 5823 to $50 \%, 0 \%$, and $0 \%$ of the control. C: Inhibitory effect of Gin C $(40,100$, and $200 \mathrm{mg} / \mathrm{mL})$ on OXT-induced contractions was not affected by bisindolylmaleimie II (Bis II), which is a PKC inhibitor. In the presence of Bis II $(0.5 \mu \mathrm{M})$, Gin C (40 and $100 \mathrm{mg} / \mathrm{mL})$ inhibited OXT-induced contractions to $36 \%$ and $1 \%$ of the control.

Figure 4: Inhibitory effects of ginger extract (Gin C) on Oxytocin (OXT)-induced contractions of mouse uterine smooth muscle. 
Inhibitory Effects of Gin C on Oxt-Induced Mouse Uterine Longitudinal Smooth Muscle Contractions in The Presence of Protein Kinase Inhibitors

Inhibitory effects of Gin C on OXT-induced contractions were studied in the presence of KT 5823 and KT 5720 known to inhibit protein kinase G (PKG) and PKA, respectively. OXT-induced contraction was inhibited by Gin $C$ at 40, 100 and $200 \mathrm{mg} / \mathrm{l}$ in the presence of KT 5823 to $50 \pm 20.8 \%, 0 \%$, and $0 \%$ of the control, respectively ( $n=4,3$, and 2 , respectively, $p<0.05$; Figure 4 C). OXT- induced contractions in the presence of KT 5720 were inhibited by Gin C at 20, 40, 100 and $200 \mathrm{mg} / \mathrm{l}$ to $78 \pm 0.2 \%, 82 \pm 0.1 \%, 31 \pm 0.2$ $\%$, and $0 \%$ of the control, respectively $(\mathrm{p}<0.05, \mathrm{n}=5,5,5$, and 0 , respectively; data now shown). To evaluate the involvement of PKC in Gin C-induced inhibition of OXT-induced contractions, Gin C was applied in the presence of a PKC inhibitor. As shown in Figure 4C, in the presence of PKC inhibitor bisindolylmaleimie II (Bis II, $0.5 \mu \mathrm{M}$ ), Gin C at 40 and $100 \mathrm{mg} / \mathrm{l}$ inhibited OXT-induced contractions to 36 $\pm 20.9 \%$ and $1 \pm 0.8 \%$ of the control, respectively $(\mathrm{p}<0.05 ; \mathrm{n}=4$ and $\mathrm{n}=2$, respectively).

A

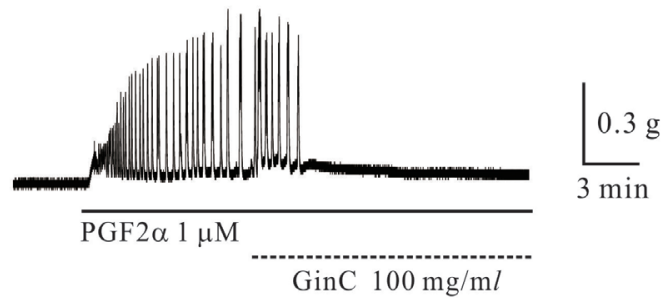

B

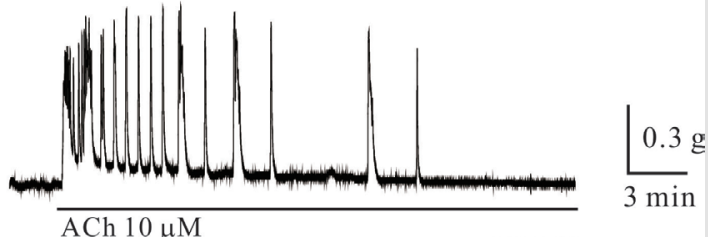

$\mathrm{ACh} 10 \mu \mathrm{M}$
GinC $4 \mathrm{mg} / \mathrm{m} l$

$\mathrm{C}$

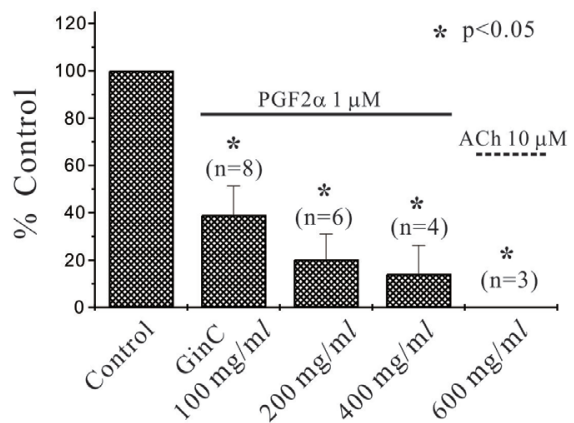

A and C: $\mathrm{PGF}_{2 \alpha}$ produced tri-phasic contractions, such as an initial contraction, followed by a tonic contraction overlapped with a phasic contraction. $\mathrm{PGF}_{2 \alpha}$-induced phasic contractions were inhibited by Gin C (100, 200, and $\left.400 \mathrm{mg} / \mathrm{mL}\right)$ to $39 \%, 20$ $\%$, and $14 \%$ of the control. B: ACh-induced phasic contraction was completely inhibited by Gin C and data as averaged in C.

Figure 5: Inhibitory effects of ginger extract (Gin C) on prostaglandin $\mathrm{F}_{2 \alpha}\left(\mathrm{PGF}_{2 \alpha}\right)$ - and induced mouse uterine smooth muscle contractions.

Inhibitory Effects of Gin $C$ on Prostaglandin $F_{2 \alpha}\left(P F_{2 \alpha}\right)-$ And Acetylcholine (ACh)-Induced Mouse Uterine Smooth Muscle Contractions

$\mathrm{PGF}_{2 \alpha}$ produced tri-phasic contractions in murine uterine smooth muscle, showing an initial contraction followed by a tonic contraction overlapped with a phasic contraction (Figure 5). $\mathrm{PGF}_{2 \alpha}$ - induced phasic contractions were inhibited by Gin C at 100, 200, and $400 \mathrm{mg} / \mathrm{l}$ to $39 \pm 12.3 \%, 20 \pm 10.8 \%$, and $14 \pm 12.0 \%$ of the control ( $n=8,8$, and 6, respectively, $\mathrm{p}<0.05$; Figure 4B). As shown in Figure 5B, Gin $\mathrm{C}$ also inhibited ACh-induced phasic contractions. In particular, Gin $C$ at $200 \mathrm{mg} / \mathrm{l}$ completely inhibited ACh-induced phasic contraction $(n=3$; Figure $5 C)$. 


\section{Discussion}

It is well known that regulation of myometrial contractility is tightly linked to $\mathrm{Ca}^{2+}$ influx and $\mathrm{Ca}^{2+}$ signaling at cellular level [18]. In this study, we found that Gin $\mathrm{C}$ inhibited contractions of murine

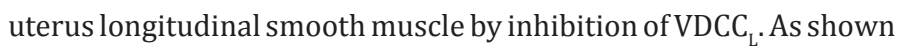
in (Figures 1 \& 2B), murine myometrial contraction was tightly related to the activation of VDCC. Well-known pharmacological blockers such as nifedipine inhibited myometrial contractions. This implies that both $\mathrm{VDCC}_{\mathrm{L}}$ is important for the regulation of myometrial contraction. In this study, Gin $\mathrm{C}$ inhibited high $\mathrm{K}^{+}$, OXT-, ACh-, and $\mathrm{PGF}_{2 \alpha}$ - induced phasic contractions. Its effect was independent of NO synthesis, protein kinases (PKA, PKG and PKC), $\mathrm{K}^{+}$channel, or nerve blockers (Figures $3 \& 4$ ). This finding suggests that Gin $\mathrm{C}$ may inhibit mouse uterine smooth muscle contractions by inhibiting $\mathrm{VDCC}_{\mathrm{L}}$ and/or $\mathrm{VDCC}_{\mathrm{T}}$ strongly. It has been reported that ginger can enhance and inhibit uterine, GI tract, and airway smooth muscle contractions by activating $\operatorname{VDCC}_{\mathrm{L}}[4,14,19]$. In the present study, we found that murine uterine spontaneous contractions and OXT-induced phasic contractions were sensitive to BayK 8644 and nifedipine (Figures 1B \& 1C).

In smooth muscle, $\mathrm{Ca}^{2+}$-induced $\mathrm{Ca}^{2+}$ release (CICR) mechanisms also known to be important to regulate smooth muscle contraction [20-22]. As shown in Figure 2B, effect of Gin C was studied in the presence of CPA too. Therefore, inhibition of murine myometrial by Gin $\mathrm{C}$ might be responsible for the inhibition of $\mathrm{VDCC}_{\mathrm{L}}$. However, in fact, effects of constituents of ginger extract on smooth muscle contractions were reported differently depending on the diverse extract. Therefore, we will also try to do some more supplementary experiments delicately by using other extracts from ginger in the future. Primary dysmenorrhea may be caused by an increase in $\mathrm{PGF}_{2 \alpha}$ produced in the uterus that can hyper contract the uterine smooth muscle and/or locally contracts blood vessels [23-24]. However, the exact mechanism of uterine spasms is currently unclear. However, phasic contraction was also sensitive to nifedipine in murine myometrium (unpublished data), Gin C inhibited $\mathrm{PGF}_{2 \alpha}{ }^{-}$ induced contractions by inhibition of $\mathrm{VDCC}_{\mathrm{L}}$. Therefore, inhibition of $\mathrm{PGF}_{2 \alpha}$-induced contractions by Gin $\mathrm{C}$ might suggests it could reduce symptoms of dysmenorrhea.

It is well known that $\mathrm{VDCC}_{\mathrm{L}}$ performs a key role in the regulation of smooth muscles [7-9]. However, the role of $\mathrm{VDCC}_{\mathrm{T}}$ in such regulation is relatively unclear. In myometrium, VDCC $_{T}$ in rat and human pregnant samples has been reported. In rat pregnant myometrium, spontaneous phasic contraction has been found to be sensitive to micromolar ranges of mibefradil [11]. Meanwhile, specific subtype of $\operatorname{VDCC}_{\mathrm{T}}\left(\mathrm{CaV}_{3.1}\right)$ and role of $\mathrm{VDCC}_{\mathrm{T}}$ in the regulation of contraction in human pregnant myometrium has been identified [25-26]. Whether the exact subtype of VDCC $_{L}$ and/or VDCC $_{\mathrm{T}}$ might be related to various conditions of myometrial contractility is not fully understood yet. Furthermore, the role of $\mathrm{VDCC}_{\mathrm{T}}$ compared to that of $\mathrm{VDCC}_{\mathrm{L}}$ in myometrial contraction is not well studied yet. In fact, even the regulation of rat pulmonary arterial proliferation is regulated by VDCC $_{\mathrm{T}}$ through activation of $\mathrm{CaV}_{3.1}$ channel [27]. We identified functional expression of $\mathrm{VDCC}_{\mathrm{L}}$ $\left(\mathrm{CaV}_{1.2}\right)$ in murine myometrium by performing mechanics and immunohistochemistry (data not shown in here). However, further study is needed to identify T-type $\mathrm{Ca}^{2+}$ channel and more functions of it in murine and human myometria.

Ginger extracts are known to have effects on the GI tract. For example, they can inhibit LES motility $[14,19]$. In these cases, serotonergic receptors and/or cholinergic $M$ receptors are involved in inhibiting smooth muscle contraction [15,28]. Ginger extract can also improve gastric emptying and IBS for gastric and intestinal motility, respectively [12-13]. That implies ginger extract might produce increasing and decreasing functions of smooth muscle via affecting receptor levels too. However, we found Gin C specifically inhibited murine myometrial contraction by inhibition of VDCCL. Ginger plant has been used to treat inflammation, rheumatic disorders, and diarrhea in traditional medicine $[2,4,29]$. Zingerone is thought to be the active antidiarrheal component responsible for limiting endotoxin-induced diarrhea [30-31]. Therefore, some effects of ginger extracts are not direct on smooth muscle. Meanwhile, gingerol produces dual effects (enhancing and inhibitory) on ileal contractions in guinea-pig [12-13] through capsaicin-sensitive neurons [32]. Shogaol- [6] from ginger can also inhibit vascular smooth muscle proliferation by activating specific signaling pathways [16].

A cyclooxygenase-related system in vascular smooth muscle may be involved in regulating eicosanoid-induced contraction [16]. Additionally, gingerols exhibit various effects on the cardiovascular system [16] while zingerone may activate the same capsaicin receptors and/or a common pathway in trigeminal ganglion neurons [32]. Some other Gin C components such as ginerols and/or shogaol could also inhibit uterine contractility. Therefore, extracts from ginger produces diverse effects on different organs via various actions. From these results, we tried to exclude involvement of nerves and other $\mathrm{K}^{+}$channels by other ginger extracts [33]. As shown in Figure 3B \& 3D, the relaxing effect of ginger extract was studied in the presence of TEA, nerve blocker cocktail. In addition, involvement of nitric oxide (NO) in the action of antinocipective activity by ginger extract was also reported [34]. Therefore, we also studied and found inhibitory effects of Gin $\mathrm{C}$ in the presence of and L-NAME $(100 \mu \mathrm{M})$ on murine uterine smooth muscle (Figure 3C). Our results suggest that Gin C may produce murine uterine relaxation by inhibiting $\operatorname{VDCC}_{\mathrm{L}}$. This is first report showing that inhibition of uterine smooth muscle contractility by ginger extract obtained by dichloromethane fraction (Gin C). Our results revealed the possibility that Gin $\mathrm{C}$ inhibited High $\mathrm{K}^{+}$-, OXT-, $\mathrm{PGF}_{2 \alpha^{-}}$, and ACh-induced uterine contraction and spontaneous contraction of uterine longitudinal smooth muscle of mouse by inhibiting $\mathrm{VDCC}_{\mathrm{L}}$.

\section{Conflicts of interest}

The authors declare that there is no conflict of interest. 


\section{Acknowledgement}

Seung Hwa Hong, Kyu Sang Kyeong, Bang Yeon Hwang equally contributed to this work.

\section{Reference}

1. Chandel KPS, Shukla G, Sharma N (1996) Biodiversity in medical and aromatic plants in India. New Delhi, India: ICAR.

2. Duka JA (2002) Handbook of medicinal herbs. CRD press. Boca Raton 327-329.

3. Felter HW (1992) The ecletic material media, pharmacology and therapeutics. Southwest School of Botanical Meicine. Bisbee 460-461.

4. Ghayur MN, Gilani AH (2005) Pharmacological basis for the medicinal use of ginger in gastrointestinal disorders. Dig Dis Sci 50(10): 18891897.

5. Lijuan W, Kipittayanant P, Chdapngse N, Wray S, Kupittayanant S, et al. (2011) The effects of wild ginger (Costus speciosus (Koen) Smith) Rhizome extract and disogenin on rat uterine contractions. Reprod Sci 18(6): 516-524.

6. Tewari, P, Prasad DN, Chaturvedi C, Das PK (1967) Preliminary studies on the uterine activity of Gloriosa superba Linn. And its adulterant Costus speciosus Sm J Res Indain Med 1: 196-202.

7. Kim YC, Koh SD, Sanders KM (2002) Voltage-dependent inward currents of interstitial cells of Cajal from murine colon and small intestine. J Physiol 541(3): 797-810.

8. Kim YC, Sim JH, Kim YH, Kwon SC, Lee SJ, et al. (2007) Effects of polyamines on contractility of guinea-pig gastric smooth muscle. J Kor Med Sci 22(1): 48-56

9. Kim YC, Suzuki H, Xu WX, Hashitani, H, Choi W, et al. (2008) Voltagedependent Ca Current Identified in Freshly Isolated Interstitial Cells of Cajal (ICC) of Guinea-pig Stomach. Kor J Physiol Pharmacol 12(6): 323330.

10. Lee SE, Kim DH, Kim YC, Han JH, Choi W, et al. (2014) H2 ReceptorMediated Relaxation of Circular Smooth Muscle in Human Gastric Corpus: The Role of Nitric Oxide (NO). Korean J Physiol Pharmacol 18(5): 425-430.

11. Lee SE, Ahn DS, Lee YH (2009) Role of T-type Ca Channels in the Spontaneous Phasic Contraction of Pregnant Rat Uterine Smooth Muscle. Korean J Physiol Pharmacol 13(3): 241-249.

12. Banji D, Banji OJK, Pavani B, Kumar ChK, Annamalai AR, et al. (2014) Zingerone regulayes intestinal transit, attenuates behavioral and oxidative perturbations in irritable bowel disorder in rats. Phytomedicine 21(4): 423-429.

13. Satoh K, Kase Y, Hayakawa T, Murata P, Ishige A, et al. (2001) Dai-kenchuto enhances acceleratd small intestinal movement. Biol Pharm Bull 24(10): 1122-1126.

14. Lohsiriwat S, Rukkiat M, Chaikomin R, Leelakusolvong S (2010) Effect of ginger on lower esophageal sphincter pressure. J Med Assoc Thai 93(3): 366-372.

15. Pertz HH, Lehmann J, Roth Ehrang R, Elz S (2011) Effects of ginger constituents on the gastrointestinal tract: role of cholinergic M3 and serotonergic 5- $\mathrm{HT}_{3}$ and 5- $\mathrm{HT}_{4}$ receptors. Planta Med 77(10): 973-978.

16. Kimura I, Kimura M, Pancho LR (1989) Modulation of eicosanoidinduced contraction of mouse and rat blood vessles by gingerols. Japan J Pharmacol 50(3): 253-261.

17. Pancho LR, Kimura I, Unno R, Kurono M, Kimura M, et al. (1989) Reversed effects between crude and processed ginger extracts on $\mathrm{PGF}_{2 \alpha}$-induced contraction in mouse mesenteric veins. Japan J Pharmacol 50(2): 243246 .

18. Shmigol AV, Eisner DA, Wray S (2001) Simultaneous measurements of changes in sarcoplasmic reticulum and cytosolic. J Physiol 531(3): $707-$ 713

19. Ghayur MN, Gilani AH, Janssen LJ (2008) Ginger attenuates acetylcholineinduced contraction and $\mathrm{Ca}^{2+}$ signaling in murine airway smooth muscle cells. Can J Pharmacol 86(5): 264-271.

20. Gravina FS, van Helden DF, Kerr KP, de Oliveira RB, Jobling P, et al. (2014) Phasic contractions of the mouse vagina and cervix at different phases of the estrus cycle and during late pregnancy. PLoS One 9: e111307.

21. Kim SJ, Ahn JM, Kim YC, Park SJ, Choi JY, et al. (1998) Relationship between global cytosolic $\mathrm{Ca}^{2+}$ concentration and $\mathrm{Ca}^{2+}$-activated $\mathrm{K}^{+}$current in rabbit cerebral arterial myocyte. J Smooth Muscle Res 34(4):159-172.

22. Matthew A, Shmygol A, Wray S (2004) $\mathrm{Ca}^{2+}$ entry, efflux and release in smooth muscle. Biol Res 37(4): 617-624.

23. Hong SH, Kyeong KS, Kim CH, KimYC, Choi W, et al. (2016) Regulation of myometrial contraction by ATP-sensitive potassium $\left(\mathrm{K}_{\mathrm{AT}} \mathrm{P}\right)$ channel via activation of SUR2B and Kir 6.2 in mouse. J Vet Med Sci 78(7): 11531159.

24. Wray S (2015) Insights from physiology into myometrial function and dysfunction. Exp Physiol 100(12):1468-1476.

25. Blanks AM, Zhao ZH, Shmygol A, Bru Mercier G, Astle S, et al. (2007) Characterization of the molecular and electrophysiological properties of the T-type calcium channel in human myometrium. J Physiol 581(3): 915-926.

26. Monir Bishty E, Pierce SJ, Kupittayanant S, Shmygol A, Wray S, et al. (2003) The effects of metabolic inhibition on intracellular calcium and contractility of human myometrium. BJOG. 110(12): 1050-1056.

27. Pluteanu F, Cribbs LL (2011) Regulation and function of Cav $_{31}$ T-type calcium channels in IGF-I-stimulated pulmonary artery smooth muscle cells. Am J Physiol Cell Physiol 300(3): C517-C525.

28. Huang QR, Iwamoto M, Aoki S, Tnaka N, Tajima K, et al. (1991) Anti-5hydroxytryptamine ${ }_{3}$ effect of galanolactone, diterpenoid isolated from ginger. Chem Pharm Bull 39(2): 397-399.

29. Chopra A, Saluja M, Tillu G, Venugopalan A, Narsimulu G, et al. (2012) Comparable efficacy of standardized Ayurveda formulation and hydroxychloroquine sulfate (HCQS) in the treatment of rheumatoid arthritis (RA): a randomized investigator-blind controlled study. Clin Rheumatol 31(2): 259-269.

30. Chen JC, Huang LJ, Wu SL, Kuo SC, Ho TY, et al, (2007) Ginger and its bioactive component inhibit enterotoxigenic Escherichia coli heat-labile enterotoxin-induced diarrhea in mice. J Agric Food Chem 55(21): 8390 8397.

31. Cho JH, Zhang S, Kim IH (2012) Effects of anti-diarrhoeal herbs on growth performance, nutrient digestibility, and meat quality in pigs. Asian-Aust. J Anim SCi 25(11): 1595-1604

32. Someya A, Horie S, Yamamoto H, Murayama T (2003) Modifications of capsicin-sensitive neurons in isolated guinea pig ileum by [6]-Gingerol and Lafutidine. J Pharmacol Sci 92(4): 359-366.

33. Kyeong KS, Hong SH, Kim YC, Cho W, Myung SC, et al. (2016) Myometrial relaxation of mice via expression of two pore domain acid sensitive $\mathrm{K}(+)$ (TASK-2) channels. Korean J Physiol Pharmacol 20(5): 547-556.

34. Khalid MH, Akhtar MN, Mohamad AS, Perimal EK, Akira A, et al. (2011) Antinociceptive effect of the essential oil of Zingiber zerumbet in mice: possible mechanisms. J Ethnopharmacol 137(1): 345-351. 
ISSN: 2574-1241

DOI: 10.26717/BJSTR.2019.20.003499

YC Kim. Biomed J Sci \& Tech Res

(C) (P) This work is licensed under Creative

Submission Link: https://biomedres.us/submit-manuscript.php

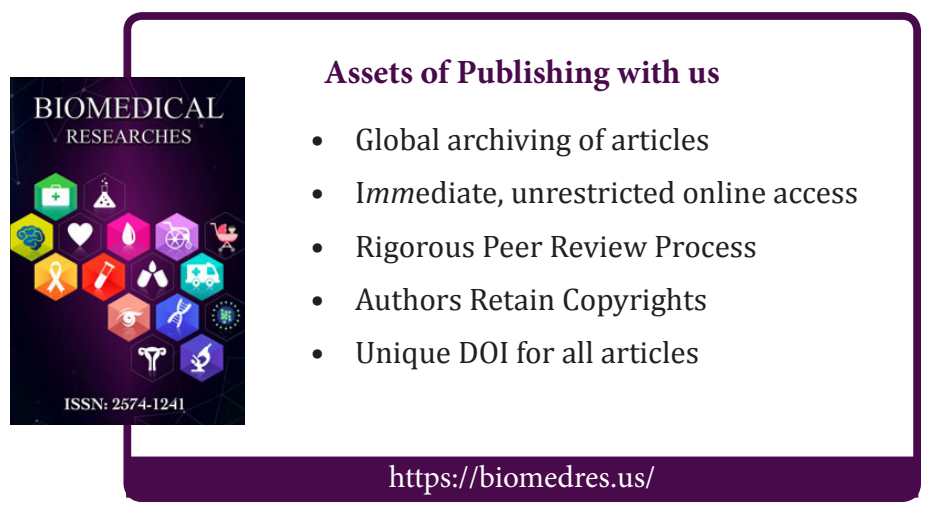

